\title{
Effect of water availability and temperature on the genotype-by-environment interaction of pearl millet in semi-arid tropical environments ${ }^{*}$
}

\author{
E.J. van Oosterom, V. Mahalakshmi, F.R. Bidinger \& K.P. Rao \\ International Crops Research Institute for the Semi-Arid Tropics (ICRISAT), Patancheru, Andhra Pradesh \\ 502324, India
}

Received 20 April 1994; accepted 14 September 1995

Key words: escape, genotype-by-environment interaction, pearl millet, Pennisetum glaucum, soil water availability, stress, temperature

\section{Summary}

Grain yields in drought-affected environments are often characterized by large genotype-by-environment (GE) interactions, caused by a highly variable timing and intensity of stress occurrence. The aim of our study was to assess the effectiveness of simple meteorological environmental descriptions in providing an understanding of the environmental contribution to the GE interaction of pearl millet (Pennisetum glaucum (L.) R. Br.) in the semi-arid tropics. The experiment comprised fourteen genotypes, grown across 24 environments in India. Data on water availability throughout the season and maximum temperatures during grain filling were used to describe the environments. Escape from drought and heat stress were the major factors determining the GE interaction. Both the timing and intensity of stress occurrence were important. Knowledge of the environmental causes of the GE interaction may facilitate the identification of adaptive plant traits, and may also enable a more rational choice of test locations for breeding programs.

\section{Introduction}

Yield gains in many drought affected agricultural production systems are hampered by relatively large genotype-by-environment (GE) interactions (Smith et al., 1990). Low yields are common in such environments, but the prevalent abiotic stress factors causing them are highly variable (Bidinger et al., 1982; Van Oosterom et al., 1993a). To cope with these GE interactions, breeders often conduct yield trials across a wide range of environments, which must represent the full spectrum of conditions encountered in their target region.

Multi-environment trials are expensive to conduct, and a proper choice of representative test locations is therefore important. To identify groups of environments with little GE interaction for grain yield, environments which rank genotypes similarly are preferably grouped together (Fox \& Rosielle, 1982). Often, however, little consideration is given in the GE analy-

* ICRISAT Journal Article 1648 ses to the underlying environmental causes leading to the grouping. This makes extrapolation of the results to other environments difficult.

Knowledge of the environmental contribution to yield and yield stability is important to plant breeders if this contribution can be linked to plant traits. This will enable breeders to adjust their selection of plant types to the prevalent stress factors in their target environment. In environments where timing and intensity of stress occurrence are unpredictable, this requires an integration of analyses of GE interactions with a characterization of occurrence of stress patterns (Muchow et al., 1996). A GE analyses that incorporates meteorological parameters can thus be part of a chain of analyses that ultimately results in an identification of plant types, adapted to a certain region (Van Oosterom et al., 1996b).

In this study, we have analysed the GE interaction for grain yield of pearl millet across 24 semi-arid tropical environments in terms of water availability and temperature. The aim was to assess how effectively 
the environmental contribution to the GE interaction in these environments can be explained when environmental descriptions are based on meteorological data, routinely collected by most weather stations.

\section{Materials and methods}

\section{Plant material and environments}

Details of the genotypes and environments used were presented in a previous paper (Van Oosterom et al., 1996a). In short, 14 pearl millet (Pennisetum glaucum (L.) R. Br.) genotypes (seven hybrids and seven open-pollinated varieties) were grown in 24 primarily drought-prone environments (location $\times$ year $\times$ management combinations) in north and south India. Twenty of the experiments were conducted during the rainy season and, with one exception, were rainfed. Four experiments were conducted during the dry season and received additional irrigation. Total seasonal rainfall, including irrigation, ranged from 110 to $719 \mathrm{~mm}$. The environments differed in timing and intensity of the occurrence of water stress and in the maximum temperatures during grain filling (Van Oosterom et al., 1996a).

The experiments were laid out as a randomized complete block design with either three or four replications.

\section{Crop water satisfaction index}

The amount of crop-available soil water was calculated using a water budget developed by Frère \& Popov (1979) and described by Van Oosterom et al. (1996a). This budget, which requires daily data on rainfall and pan evaporation as input, calculates a cumulative water satisfaction index (WSI), which is set to 100 at sowing and declines if water deficits occur. Deficits are expressed as a percentage of the seasonal water requirement. The changes in WSI before flowering and during grain filling enable an estimate to be made of the magnitude of the pre- and post-flowering drought stress. WSI at maturity was three times more effective in explaining yield differences between environments than was actual seasonal rainfall (Van Oosterom et al., 1996a).
Table 1. Name, type, mean grain yield $\left(\mathrm{g} / \mathrm{m}^{2}\right)$ and mean time from sowing to flowering $\left({ }^{\circ} \mathrm{Cd}\right.$ ), and the value for interaction principal component 1 (IPCA1) of the AMMI analysis for grain yield for the genotypes used in the experiments. Genotypes are ranked by IPCAl for grain yield

\begin{tabular}{|c|c|c|c|c|}
\hline \multirow[t]{2}{*}{ Genotype } & \multirow[t]{2}{*}{ Type $^{a}$} & \multicolumn{2}{|c|}{ Grain yield } & \multirow{2}{*}{$\begin{array}{l}\text { Time to } \\
\text { flowering } \\
{ }^{\circ} \mathrm{Cd}\end{array}$} \\
\hline & & $\begin{array}{l}\text { Mean } \\
\text { g/m }\end{array}$ & IPCA1 & \\
\hline \multicolumn{5}{|c|}{ Early flowering } \\
\hline НHВ 67 & HYB & 236 & -9.58 & 664 \\
\hline ННВ 68 & HYB & 230 & -4.93 & 711 \\
\hline RHB 27 & HYB & 221 & -4.45 & 667 \\
\hline \multicolumn{5}{|c|}{ Medium flowering } \\
\hline RHB 23 & HYB & 205 & -4.04 & 762 \\
\hline CZDT 46 & VAR & 172 & -3.87 & 763 \\
\hline ICMV 88904 & VAR & 216 & -2.73 & 773 \\
\hline НHB 60 & HYB & 234 & -0.97 & 795 \\
\hline RHB 28 & HYB & 202 & 0.98 & 776 \\
\hline \multicolumn{5}{|l|}{ Late flowering } \\
\hline PSB 1 & VAR & 181 & -0.36 & 871 \\
\hline IHPV 85/1 & VAR & 203 & 2.48 & 849 \\
\hline ICMV 87125 & VAR & 214 & 4.69 & 842 \\
\hline WC - C75 & VAR & 193 & 6.47 & 867 \\
\hline ICMH 84122 & HYB & 236 & 7.03 & 865 \\
\hline ICMV 82113 & VAR & 193 & 9.27 & 882 \\
\hline
\end{tabular}

${ }^{a}$ HYB, hybrid; VAR, variety.

\section{Classification of environments and genotypes}

Based on the seasonal pattern of water availability, four clusters of environments were identified (Van Oosterom et al., 1996a): cluster 1 (ten environments) was composed of environments without drought stress; cluster 2 contained nine environments with moderate post-flowering drought stress; cluster 3 three environments with severe post-flowering drought stress; and cluster 4 two environments with severe pre-flowering drought stress. These groups were further subdivided based upon mean maximum temperature during grain filling.

To account for the differences in flowering dates among genotypes ( 9 to 23 days, depending on the environment), the genotypes were divided into three phenology classes (Table 1): early ( 3 genotypes), medium (5), and late flowering (6). The range in flowering dates within each of these three classes in an environment was in general less than 7 days and never exceeded 11 days. 
Table 2. Mean and value of the first interaction principal component (IPCA1) for grain yield, correlation coefficient between grain yield and time to flowering for 24 environments, ranked for IPCA1 for grain yield. The clustering is based on water availability

\begin{tabular}{|c|c|c|c|c|}
\hline \multirow[t]{2}{*}{ Environment } & \multirow[t]{2}{*}{ Cluster $^{a}$} & \multicolumn{2}{|c|}{ Grain yield } & \multirow{2}{*}{$\begin{array}{l}\text { Corr. } \\
\text { coeff. }\end{array}$} \\
\hline & & $\begin{array}{l}\text { Mean } \\
\mathrm{g} / \mathrm{m}^{2}\end{array}$ & IPCA1 & \\
\hline Hisar 88 irrigated & 1 & 354 & -7.45 & -0.63 \\
\hline Fatehpur 88 & 2 & 212 & -4.96 & -0.84 \\
\hline Mandor 88 & 3 & 91 & -4.31 & -0.79 \\
\hline Jodhpur 88 & 3 & 63 & -4.21 & -0.89 \\
\hline Hisar 88 & 1 & 241 & -3.87 & -0.68 \\
\hline \multicolumn{5}{|l|}{ Patancheru } \\
\hline dry season 90 stress $^{b}$ & 2 & 148 & -3.29 & -0.77 \\
\hline \multicolumn{5}{|l|}{ Patancheru } \\
\hline dry season 89 control & 1 & 319 & -2.59 & -0.63 \\
\hline \multicolumn{5}{|l|}{ Patancheru } \\
\hline dry season 89 stress $^{b}$ & 2 & 170 & -1.46 & -0.75 \\
\hline Jobner 88 & 2 & 63 & -1.31 & -0.56 \\
\hline \multicolumn{5}{|l|}{ Patancheru } \\
\hline dry season 90 control & 1 & 283 & -0.62 & -0.24 \\
\hline Patancheru 89 stress $^{c}$ & 2 & 168 & -0.51 & -0.08 \\
\hline Anantapur 89 late sowing & 2 & 183 & -0.43 & -0.39 \\
\hline Anantapur 88 late sowing & 2 & 192 & -0.23 & -0.27 \\
\hline Bawal 88 & 1 & 318 & 0.07 & -0.28 \\
\hline Mandor 89 & 3 & 124 & 0.18 & -0.36 \\
\hline Durgapura 89 & 2 & 82 & 0.91 & -0.05 \\
\hline Anantapur 88 early sowing & 1 & 273 & 0.97 & -0.01 \\
\hline Jamnagar 89 & 2 & 291 & 1.39 & -0.02 \\
\hline Fatehpur 89 & 4 & 47 & 2.23 & 0.51 \\
\hline Jamnagar 88 & 1 & 267 & 3.19 & 0.49 \\
\hline Patancheru 88 & 1 & 313 & 3.34 & 0.14 \\
\hline Anantapur 89 early sowing & 4 & 81 & 3.85 & 0.36 \\
\hline Patancheru 89 & 1 & 427 & 8.83 & 0.41 \\
\hline Durgapura 88 & 1 & 324 & 10.28 & 0.43 \\
\hline
\end{tabular}

$a$, no drought stress; 2 , moderate post-flowering drought stress; 3 , severe postflowering drought stress; 4 , pre-flowering drought stress. ${ }^{b}$ Irrigated until average flowering date only. ${ }^{C}$ Protected from rain after average flowering via rain-out shelter.

Because the phenology classes encountered different levels of stress, water availability patterns and mean maximum temperatures during grain filling were estimated separately for each phenology class at each environment. The upper limit for grain yield at a certain WSI (at maturity) was for each phenology class expressed as a function of yield potential and of yield reduction due to pre- and post-flowering drought stress, using a multiple regression analysis. For each phenology class, environments were only included in the regression if the concerned genotypes had a higher average grain yield in that environment than in any of the environments with a lower WSI at maturity for that phenology class.

\section{Genotype-by-environment interaction}

The GE interaction for grain yield was analysed using the additive main effects and multiplicative interaction (AMMI) model (Gauch, 1988; Zobel et al., 1988). In this model, main effects are analyzed with an analysis of variance and their interaction with a principal com- 
Table 3. Correlation coefficient between grain yield and time to flowering, and mean maximum temperature during the first ten days after flowering for early, medium, and late flowering pearl millet entries in environments without major drought stress (cluster 1)

\begin{tabular}{lllll}
\hline \multirow{2}{*}{ Environment } & \multirow{2}{*}{$\begin{array}{l}\text { Corr. } \\
\text { coeff. }\end{array}$} & \multicolumn{3}{l}{ Max. temperature } \\
\cline { 3 - 5 } & $-0.68^{* *}$ & 34.1 & 33.8 & 35.7 \\
\hline Hisar 88 & $-0.63^{*}$ & 33.8 & 33.8 & 35.1 \\
Hisar 88 irrigated & & & & \\
Patancheru & $-0.63^{*}$ & 31.9 & 33.0 & 35.4 \\
dry season 89 control & -0.28 & 31.3 & 32.4 & 34.1 \\
Bawal 88 & & & & \\
Patancheru & -0.24 & 34.1 & 35.2 & 35.9 \\
dry season 90 control & -0.01 & 31.2 & 30.4 & 30.6 \\
Anantapur 88 early sowing & 0.14 & 27.0 & 29.4 & 30.0 \\
Patancheru 88 & 0.41 & 28.6 & 28.0 & 27.5 \\
Patancheru 89 & 0.43 & 30.7 & 30.7 & 31.7 \\
Durgapura 88 & $0.49+$ & 31.8 & 31.6 & 31.6 \\
Jamnagar 88 & & & & \\
\hline
\end{tabular}

$+\mathrm{P}<0.10 ; * \mathrm{P}<0.05 ;{ }^{* *} \mathrm{P}<0.01$

Table 4. Correlation coefficient between grain yield and time to flowering, mean maximum temperature during the first ten days after flowering and relative water deficit during grain filling for early, medium, and late flowering pearl millet entries in environments with moderate post-flowering drought stress (cluster 2)

\begin{tabular}{|c|c|c|c|c|c|c|c|}
\hline \multirow[t]{2}{*}{ Environment } & \multirow{2}{*}{$\begin{array}{l}\text { Corr. } \\
\text { coeff. }\end{array}$} & \multicolumn{3}{|c|}{ Max. temperature } & \multicolumn{3}{|c|}{ Rel. water deficit } \\
\hline & & Early & Medium & Late & Early & Medium & Late \\
\hline Fatehpur 88 & $-0.84 * * *$ & 32.9 & 33.5 & 34.2 & 29.2 & 33.8 & 35.8 \\
\hline \multicolumn{8}{|l|}{ Patancheru } \\
\hline dry season 90 stress & $-0.77 * *$ & 34.1 & 35.2 & 35.6 & 33.0 & 42.8 & 45.2 \\
\hline \multicolumn{8}{|l|}{ Patancheru } \\
\hline dry season 89 stress & $-0.75^{* *}$ & 32.4 & 31.3 & 33.8 & 28.7 & 38.4 & 43.0 \\
\hline Jobner 88 & $-0.56^{*}$ & 32.2 & 33.0 & 35.9 & 20.4 & 28.2 & 32.2 \\
\hline Anantapur 89 late sowing & -0.39 & 31.5 & 32.2 & 33.5 & 15.4 & 19.3 & 32.3 \\
\hline Anantapur 88 late sowing & -0.27 & 31.1 & 31.6 & 32.6 & 27.1 & 33.8 & 38.5 \\
\hline Patancheru 89 stress & -0.08 & 28.6 & 28.2 & 27.5 & 34.9 & 36.9 & 39.4 \\
\hline Durgapura 89 & -0.05 & 32.3 & 34.2 & 36.4 & 21.4 & 33.3 & 43.6 \\
\hline Jamnagar 89 & -0.02 & 31.7 & 32.2 & 31.9 & 24.2 & 26.4 & 26.5 \\
\hline
\end{tabular}

$* \mathrm{P}<0.05 ; * * \mathrm{P}<0.01 ; * * * \mathrm{P}<0.001$

ponent analysis (PCA). The interaction between any genotype and environment can be estimated by multiplying the score for the interaction principal component axis (IPCA) of a genotype by an environment IPCA score. If a particular genotype and environment have a similar sign for an IPCA, their interaction is positive; if the sign is opposite, the interaction is negative. Because the data set was unbalanced due to different numbers of replications, the AMMI analysis was per formed on the means over replications. 
Table 5. Correlation coefficient between grain yield and time to flowering, mean maximum temperature during the first ten days after flowering and relative water deficit during the 20 days before flowering and during grain filling for early, medium, and late flowering pearl millet entries in environments with severe post-flowering drought stress (cluster 3 )

\begin{tabular}{|c|c|c|c|c|c|c|c|c|c|c|}
\hline \multirow[t]{3}{*}{ Environment } & \multirow{3}{*}{$\begin{array}{l}\text { Corr. } \\
\text { coeff. }\end{array}$} & & & & \multicolumn{6}{|c|}{ Relative water deficit } \\
\hline & & \multicolumn{3}{|c|}{ Max. temperature } & \multicolumn{3}{|c|}{ Pre-flowering } & \multicolumn{3}{|c|}{ Post-flowering } \\
\hline & & $\begin{array}{l}\text { Early } \\
{ }^{\circ} \mathrm{C}\end{array}$ & $\begin{array}{l}\text { Medium } \\
{ }^{\circ} \mathrm{C}\end{array}$ & $\begin{array}{l}\text { Laste } \\
{ }^{\circ} \mathrm{C}\end{array}$ & $\begin{array}{l}\text { Early } \\
\%\end{array}$ & $\begin{array}{l}\text { Medium } \\
\%\end{array}$ & $\begin{array}{l}\text { Late } \\
\%\end{array}$ & $\begin{array}{l}\text { Early } \\
\%\end{array}$ & $\begin{array}{l}\text { Medium } \\
\%\end{array}$ & $\begin{array}{l}\text { Late } \\
\%\end{array}$ \\
\hline Jodhpur 88 & $-0.89 * * *$ & 35.9 & 36.5 & 38.2 & 2.8 & 4.1 & 10.2 & 46.1 & 49.0 & 43.9 \\
\hline Mandor 88 & $-0.79 * * *$ & 35.9 & 35.9 & 38.3 & 8.4 & 4,9 & 12.6 & 39.8 & 51.1 & 49.4 \\
\hline Mandor 89 & -0.36 & 34.0 & 35.6 & 36.0 & 0.0 & 4.0 & 5.1 & 32.9 & 36.9 & 38.8 \\
\hline
\end{tabular}

$* * * \mathrm{P}<0.001$.

Table 6. Correlation coefficient between grain yield and time to flowering, mean maximum temperature during the first ten days after flowering, relative water deficit from sowing until 20 days before flowering, during the 20 days before flowering, and during grain filling, and water sufficiency index (WSI) at flowering and maturity for early, medium, and late flowering pearl millet in environments with pre-flowering drought (cluster 4)

\begin{tabular}{|c|c|c|c|c|c|c|}
\hline \multirow[t]{3}{*}{ Correlation coefficient } & \multicolumn{3}{|c|}{ Anantapur 1989 (early) } & \multicolumn{3}{|c|}{ Fatehpur 1989} \\
\hline & \multicolumn{3}{|c|}{0.36} & \multicolumn{3}{|c|}{$0.51+$} \\
\hline & Early & Medium & Late & Early & Medium & Late \\
\hline Mean max temperature $\left({ }^{\circ} \mathrm{C}\right)$ & 33.5 & 32.2 & 33.5 & 34.4 & 33.1 & 33.9 \\
\hline \multicolumn{7}{|l|}{ Water deficit $(\%)$} \\
\hline Sowing - $20 \mathrm{~d}$. before flow. & 7.2 & 12.6 & 16.0 & 9.4 & 16.0 & 18.6 \\
\hline $20 \mathrm{~d}$. before flow.-flow. & 32.5 & 30.2 & 22.7 & 34.4 & 21.4 & 16.2 \\
\hline grain filling & 20.6 & 13.6 & 12.7 & 22.8 & 28.9 & 33.8 \\
\hline WSI at flowering & 60.4 & 57.3 & 61.3 & 56.2 & 62.7 & 65.2 \\
\hline WSI at maturity & 39.7 & 43.7 & 48.6 & 33.4 & 33.7 & 31.4 \\
\hline
\end{tabular}

$+P<0.10$.

\section{Results}

\section{Genotypic and environmental components of the $G E$} interaction for grain yield

The classification of environments into four groups based on the seasonal pattern of water availability, which explained $75 \%$ of the environmental sum of squares (SS) (Van Oosterom et al., 1996b), explained only $16 \%$ of GE interaction SS. This indicates that the occurrence of drought per se, although effective in explaining environmental mean grain yield, had little effect on the GE interaction, suggesting that other environmental factors were involved in determining the $\mathrm{GE}$ interaction.

The first interaction principal component (IPCA1) for grain yield explained $40.1 \%$ of the interaction sum of squares (SS), nearly three times the percentage explained by IPCA2 (15.4\%). The analyses of the GE interaction will therefore focus on IPCA1 only.

The genotypic part of IPCA1 (Table 1) was not correlated with genotypic mean grain yield $(r=-0.24, P$ $>0.10)$, but strongly positively $(r=0.88, P<0.001)$ associated with genotypic mean time to flowering. The environmental part of IPCA1 (Table 2) was not correlated with environmental mean yield $(r=0.29, P$ $>0.10$ ), but it was negatively associated with the mean maximum temperature during the first ten days after flowering $(r=-0.63, P<0.01)$ and with the change in WSI during grain filling $(r=-0.41, p<0.05)$. In addition, the correlation coefficient in a particular environment between flowering and grain yield was very closely associated with IPCA1 $(\mathrm{r}=0.87, \mathrm{P}<0.001$, Table 2). 
Table 7. Multiple regression of pre- and post-flowering water deficits on the maximum grain yield at that water deficit for three phenology classes of pearl millet, grown across a range of semi-arid tropical environments in India

\begin{tabular}{|c|c|c|c|c|}
\hline \multirow[t]{2}{*}{ Genotypes } & \multirow[t]{2}{*}{$\begin{array}{l}\text { Adjusted } \\
\mathrm{R}^{2}\end{array}$} & \multirow{2}{*}{$\begin{array}{l}\text { Yield } \\
\text { potential } \\
\left(\mathrm{g} / \mathrm{m}^{2}\right)\end{array}$} & \multicolumn{2}{|c|}{$\begin{array}{l}\text { Yield reduction } \\
\text { ( } \mathrm{g} / \mathrm{m}^{2} / \% \text { water deficit) }\end{array}$} \\
\hline & & & Pre & Post \\
\hline All $(6)^{a}$ & 0.974 & 428 & 5.39 & 5.73 \\
\hline Early (13) & 0.981 & $395^{* *}$ & 5.63 & $5.01 *$ \\
\hline Medium (12) & 0.965 & 404 & 5.72 & 5.55 \\
\hline Late (11) & 0.950 & 431 & 6.04 & 5.88 \\
\hline
\end{tabular}

a Number of environments on which multiple regression is based.

${ }^{*},{ }^{* *}$, significantly different from parameter for all genotypes at $\mathrm{P}<0.05$ and $\mathrm{P}<0.01$, respectively.

\section{Analysis of the GE interaction}

The close association between time to flowering and the genotypic component of IPCA 1 indicates that, in our data set, the pattern of the GE interaction for grain yield was mainly determined by the role of stress escape. The analysis of the environmental contribution to the GE interaction will therefore focus on the importance of escape at a particular environment.

Environments where drought stress was absent (cluster 1) had a wide range in the value for IPCA1 (square symbols, Fig. 1). Late genotypes (' $\mathrm{L}$ ' in Fig. 1) had a positive interaction with some of these environments (similar sign for IPCA1 in Fig. 1), whereas in other environments early genotypes (' $E$ ' in Fig. 1) had an advantage. This contrast was associated with the maximum temperature during grain filling in these environments (open vs closed squares in Fig. 1). The environments of cluster 1 with a positive correlation between time to flowering and grain yield were characterized by relatively low temperatures during grain filling (Table 3), which were similar for the three phenology classes (except at Patancheru 1988). The advantage of earliness in the other non-droughted environments was invariably associated with a rise in temperature around flowering, as late genotypes consistently experienced higher temperatures after flowering than early ones (Table 3). Maximum temperatures in these environments were well within the range where higher temperatures negatively affect grain filling, as shown by Chowdhury \& Wardlaw (1978) for sorghum (Sorghum bicolor (L.) Moench). At Patancheru in 1988, the rise in temperature did not favour the early genotypes, apparently because the temperatures were still suboptimal. The interaction pattern of environments with- out drought stress was thus driven by escape of heat stress.

In environments where drought stress occurred after flowering (clusters 2 and 3), earliness was in general advantageous (similar sign for IPCA1 in Fig. 1 for circles and ' $E$ '). However, the range in the flowering/yield correlation ( $r=-0.89$ at Jodhpur 1988 to $r=-0.02$ at Jamnagar 1989, Tables 4 and 5) indicated that, notwithstanding the occurrence of postflowering drought, escape varied in importance. In the environments with moderate post-flowering drought stress (cluster 2) where the flowering/yield correlation was significantly negative, late genotypes consistently experienced more drought stress and higher temperatures during grain filling than early ones (Table 4). For environments where the flowering/yield correlation was not significant, the level of stress encountered was either less severe (Anantapur, Table 4) or was similar for the three phenology classes (Patancheru 1989 stress and Jamnagar 1989, Table 4). Stress escape was hence not important in these environments. Only at Durgapura 1989, however, was the absence of a relation between flowering and yield inconsistent with the escape of both drought and temperature stress by the early genotypes (Table 4 ). In environments experiencing severe post-flowering drought stress (cluster 3 ), the higher yield of early-flowering genotypes was also associated with escape of temperature and drought stress (Table 5). On a seasonal basis, earlyflowering genotypes invariably experienced the least drought stress. Depending on the environment, however, this was due to escape during either the 20-day period preceding flowering, when panicles are developing and growing (Jodhpur 1988) or during grain filling (Mandor 1988). Generally, the yield advantage of 


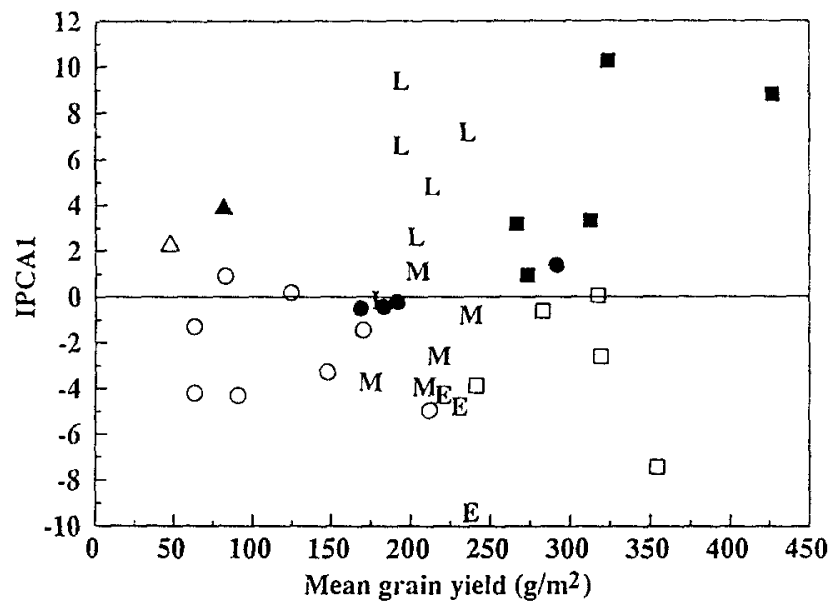

Fig. I. Biplot of the AMMI model for 14 pearl millet genotypes, grown in 24 environments in India. Environments are grouped into those without drought stress $(\square)$, with post-flowering drought stress (o), and with pre-flowering drought stress $(\Delta \mathbf{\Delta})$; closed symbols represent environments with low temperatures during grain filling (average maximum temperature $<34^{\circ} \mathrm{C}$ ), open symbols those with high temperatures during grain filling $\left(>34^{\circ} \mathrm{C}\right.$ ). Genotypes are grouped according to flowering into $\mathrm{E}$ (early), $\mathrm{M}$ (medium), and $\mathrm{L}$ (late).

early genotypes in environments having post-flowering drought stress was a combination of escape of both drought and temperature stress.

In the two environments where drought stress occurred already before flowering (cluster 4), a slow initial plant development (late flowering) was advantageous (similar sign for IPCA1 in Fig. 1 for triangles and ' $L$ '). The reason was that in these environments the severest drought spell occurred just before flowering of the early genotypes (Table 6), whereas the lateflowering genotypes experienced part of this drought stress during earlier developmental stages. Because the three phenology classes encountered similar temperatures during grain filling and similar water deficits, the relationship between time to flowering and grain yield in these environments was mainly determined by the timing of the drought stress during the pre-flowering period.

The upper limit for grain yield of a phenology class in an environment depended linearly on the WSI at maturity (Fig. 2). Hence, grain yield in this experiment was a linear function of cumulative WSI, provided water availability was the major factor limiting grain yield. Early genotypes tended to be less sensitive to post-flowering drought than the other genotypes, but that was offset by a lower yield potential (Table 7). For the medium- and late-flowering genotypes, the estimates for yield potential and response to drought did not differ significantly from each other. This confirms the observation that genotypic differences in the response to drought stress were largely due to escape, and to a limited extent due to differences in response to water supply in general.

\section{Discussion}

Escape from stress was in our study the main component determining the GE interaction. In the absence of drought, escape of high temperatures drove the interaction, whereas in water-limited environments the interaction was determined by escape of drought. Phenology was important, because the reduction in grain yield depends on the developmental stage of the plant at the time of stress occurrence. Early stages of plant development are less sensitive to drought stress than the stages just before and around flowering (Mahalakshmi et al., 1987; Craufurd \& Peacock, 1993). In the two environments in our study where pre-flowering drought occurred, the late genotypes were, at the moment of stress occurrence, in a less sensitive developmental stage than the earlier genotypes and hence escaped stress. However, occurrence of stress per se not necessarily determined the GE interaction, as illustrated by Table 4. In fact, the GE interaction was determined by other factors (temperature and water availability) than environmental mean yield (water availability alone). For breeders who are interested in the identification of appropriate test environments, a grouping based on the GE interaction matrix is more important than a grouping on the basis of yield level. Therefore, test environments should not be grouped on the basis of 


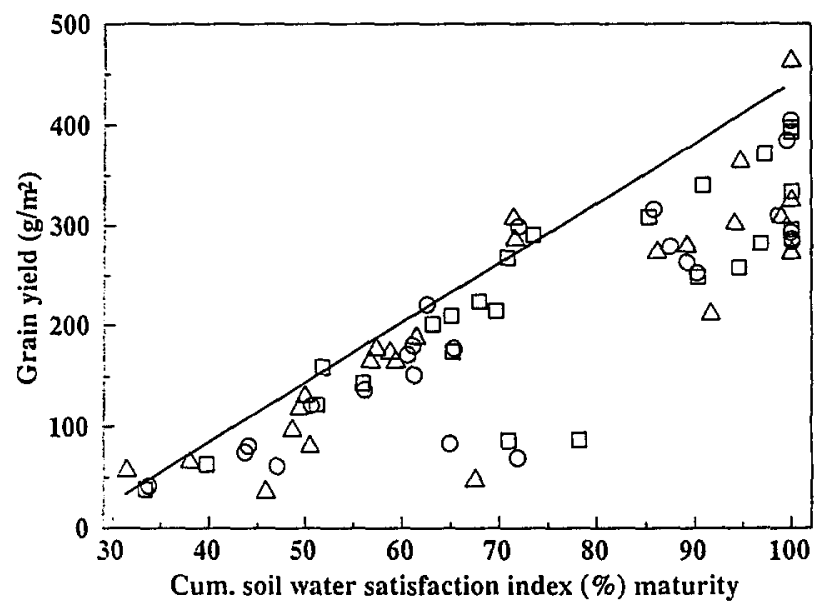

Fig. 2. Relation between grain yield $\left(\mathrm{g} / \mathrm{m}^{-2}\right)$ and cumulative soil water satisfaction index at 25 days after flowering for early ( $\square$ ), medium $(0)$, and late $(\Delta)$ flowering genotypes. The regression line for the upper limit is fitted by eye.

stress occurrence per se, but rather on the extent to which genotypes with contrasting phenology experience differential levels of stress at critical developmental stages.

Inclusion of actual meteorological data and physical descriptions of the test environments in the analysis of the GE interaction is a prerequisite for identifying the extent to which different genotypes escape stress. Studies that incorporate such data in the analysis of the interaction are scarce. Often, the environmental component of the interaction is analysed by the general, long-term climatic characteristics of the locations where the experiments were conducted (e.g. Zobel et al., 1988; Crossa et al., 1990; Shafii et al., 1992; Van Oosterom et al., 1993b). However, analyses that included actual meteorological data (e.g. Saeed \& Francis, 1984; Nachit et al., 1992; Van Eeuwijk \& Elgersma, 1993) corroborate ours that relatively simple parameters like temperature and water availability, can improve our understanding of the environmental contribution to the GE interaction for grain yield.

The importance of specific abiotic stresses for a breeding program depends on their frequency of occurrence. A limitation of multi-environment trials is that they are conducted for only a few years and are unlikely to sample the range of environments the crop can encounter, especially not in variable stress environments. The frequency of occurrence of certain stress patterns can be estimated from an analysis of longterm weather data. Muchow et al. (1996) reported for water-limited environments in subtropical Australia that an analysis of historical rainfall records in terms of relative transpiration (the ratio of actual to potential transpiration) was successful in identifying groups of years with distinct patterns and frequencies of drought occurrence. Such a characterization makes it possible to quantify the importance of an abiotic stress pattern in a certain year in terms of its long-term frequency of occurrence. A combination of GE analysis and environmental characterization can provide useful information on the importance of certain stress patterns for $\mathrm{GE}$ interaction in a particular region.

Knowledge of the impact of the timing and intensity of abiotic stresses on the GE interaction is required to enhance the efficiency of breeding programs, especially those aiming at production systems where high GE interactions arise from an unpredictable occurrence of abiotic stress. In environments where the timing and intensity of stress occurrence are predictable, phenology is an adequate escape mechanism and earliness is an important selection criterion (Ludlow \& Muchow, 1990). In case stress is unpredictable, however, developmental plasticity is required (Ludlow \& Muchow, 1990) and tillering becomes more important (Mahalakshmi \& Bidinger, 1986; Van Oosterom et al., 1996b). Plasticity at a population level can be improved by using genetically heterogeneous open-pollinated varieties or topcross hybrids (Bidinger et al., 1994), rather than uniform single-cross hybrids. In environments where the choice of genotypes not only depends on the prevalent rainfall patterns, but also on the socioeconomic needs of the farming system, village surveys and farmers' preferences can be added to the GE analyses and the environmental characterization (Van Oosterom et al., 1996b). In this scenario, analyses of GE interactions that are aimed at identifying the envi- 
ronmental component of the $\mathrm{GE}$ interaction can be an important part in a chain of analyses that can lead to a better definition of desired plant types for variable stress environments.

\section{Acknowledgements}

The authors would like to thank the cooperators, Drs. G.K. Arya, H.R. Dave, B.D. Gothwal, A.K. Joshi, P. Joshi, R.L. Kapoor, P. Sagar, M.B.L. Saxena, D.L. Singhania and K.L. Vyas for their invaluable help in data collection, and Dr. D.E. Byth for the useful comments on earlier versions of the manuscript.

\section{References}

Bidinger, F.R., V. Mahalakshmi, B.S. Talukdar \& G. Alagarswamy, 1982. Improvement of drought resistance in pearl millet. In: Drought Resistance in Crops with Emphasis on Rice, pp. 357375. IRRI, Los Baños, The Philippines.

Bidinger, F.R., E. Weltzien R., V. Mahalakshmi, S.D. Singh \& K.P. Rao, 1994. Evaluation of landrace topcross hybrids of pearl millet for arid zone environments. Euphytica 76: 215-226.

Chowdhury, S.I. \& I.F. Wardlaw, 1978. The effect of temperature on kernel development in cereals. Aust. J. Agric. Res. 29: 205-223.

Craufurd, P.Q. \& J.M. Peacock, 1993. Effect of heat and drought stress on sorghum (Sorghumbicolor (L.) Moench). 2. Grain yield. Expl. Agric. 29: 77-86.

Crossa, J., H.G. Gauch Jr. \& R.W. Zobel, 1990. Additive main effects and multiplicative interaction analysis of two international maize cultivar trials. Crop Sci. 30: 493-500.

Fox, P.N. \& A.A. Rosielle, 1982. Reducing the influence of environmental main-effects on pattem analysis of plant breeding environments. Euphytica 31: 645-656.

Frère, M. \& G.F. Popov, 1979. Agrometeorological crop monitoring and forecasting. FAO Plant Production and Protection Paper No. 17. FAO, Rome, Italy.

Gauch Jr., H.G., 1988. Model selection and validation for yield trials with interaction. Biometrics 44: 705-715.

Ludlow, M.M. \& R.C. Muchow, 1990. A critical evaluation of traits for improving crop yields in water-limited environments. Adv. Agron. 43: 107-153.
Mahalakshmi, V. \& F.R. Bidinger, 1986. Water deficit during panicle development in pearl millet: yield compensation by tillers. J. Agric. Sci., Camb. 106: 113-119.

Mahalakshmi, V., F.R. Bidinger \& D.S. Raju, 1987. Effect of timing of water deficit on pearl millet (Pennisetum americanum). Field Crops Res. 15: 327-339.

Muchow, R.C., M. Cooper \& G.L. Hammer, 1996. Characterising environmental challenges using models. In: M. Cooper \& G.L. Hammer (Eds.) Plant Adaptation and Crop Improvement. CAB International, Wallinford, UK (in press).

Nachit, M.M., M.E. Sorrells, R.W. Zobel, H.G. Gauch, R.A. Fischer \& W.R. Coffman, 1992. Association of environmental variables with sites' mean grain yield and components of genotypeenvironment interaction in durum wheat. II. J. Genet. Breed. 46: 50-55.

Saeed, M. \& C.A. Francis, 1984. Association of weather variables with genotype $\times$ environment interactions in grain sorghum. Crop Sci. 24: 13-16.

Shafii, B., M.A. Mahler, W.J. Price \& D.L. Auld, 1992. Genotype $\times$ environment interaction effects on winter rapeseed yield and oil content. Crop Sci. 32: 922-927.

Smith, M.E., W.R. Coffman \& T.C. Barker, 1990. Environmental effects on selection under high and low input conditions. In: M.S. Kang (Ed). Proc. Genotype-by-Environment Interaction and Plant Breeding Conference, February 12-13, 1990, Baton Rouge, USA, pp. 261-272. Louisiana State University, Baton Rouge, USA.

Van Eeuwijk, F.A. \& A. Elgersma, 1993. Incorporating environmental information in an analysis of genotype by environment interaction for seed yield in perennial ryegrass. Heredity $70: 447-457$.

Van Oosterom, E.J., S. Ceccarelli \& J.M. Peacock, 1993a. Yield response of barley to rainfall and temperature in Mediterranean environments. J. Agric. Sci., Camb. 121: 307-313.

Van Oosterom, E.J., D. Kleijn, S. Ceccarelli \& M.M. Nachit, 1993b. Genotype-by-environment interactions of barley in the Mediterranean region. Crop Sci. 33: 669-674.

Van Oosterom, E.J., V. Mahalakshmi, F.R. Bidinger \& K.P. Rao, 1996a. Effect of water availability pattern on yield of pearl millet in semi-arid tropical environments. Euphytica 89: 165-173.

Van Oosterom, E.J., M.L. Whitaker \& E. Weltzien R., 1996b. Integrating genotype-by-environment analysis, characterization of drought patterns, and farmer preferences to identify adaptive plant traits for pearl millet. In: M. Cooper \& G.L. Hammer (Eds.) Plant Adaptation and Crop Improvement. CAB International. Wallinford, UK (in press).

Zobel, R.W., M.J. Wright \& H.G. Gauch Jr., 1988. Statistical analysis of a yield trail. Agron. J. 80: 388-393. 